PALABRAS CLAVE

Seguridad social

Pensiones

Aportaciones de pensiones

Costos

Financiación

Reforma administrativa

Aspectos económicos

Aspectos demográficos

Caribe

Oliver Paddison

División de Análisis de Políticas

de Desarrollo,

Departamento de Asuntos

Económicos y Sociales,

Naciones Unidas

œ paddison@un.org
REVISTA DE LA CEPAL 92 •AGOSTO 2007

\section{La protección social en el Caribe de habla inglesa}

\author{
Oliver Paddison
}

$\mathrm{E}$

n los últimos años los asuntos relacionados con la protección social, y sobre todo los sistemas de pensiones, se han convertido en temas importantes de la agenda económica y política de países desarrollados y en desarrollo, a medida que en las proyecciones demográficas aparece amenazada la sostenibilidad financiera de muchos de los planes de pensiones vigentes. Sin embargo, en el Caribe estos sistemas aún no han sufrido reforma de fondo alguna. Es posible que esto obedezca en parte a la poca investigación existente sobre el tema, por lo cual las autoridades no han dispuesto de estudios acerca de cómo abordar el problema de la protección social en un entorno con las características geográficas y geoclimáticas de la región. Este trabajo busca llenar ese vacío, poniendo de relieve el estado actual de los sistemas públicos de pensiones en el Caribe, su desempeño reciente y los desafíos que les aguardan, y proponer vías para avanzar. 


\section{I}

\section{Introducción}

Los sistemas de protección social constituyen una base fundamental de la sociedad. Puesto que el consumo de las personas continúa después de la jubilación y, sobre todo, porque tras jubilarse quizás haya que afrontar gastos considerables en tratamientos médicos y otras formas de atención de la salud, se hace imperativo ahorrar durante la vida activa. Sin embargo, es poco probable que las personas acumulen de manera preventiva un volumen de ahorro suficiente durante su vida laboral. Algunas tal vez carezcan de la capacidad de actuar con previsión perfecta y por ello no tomen conciencia cabal de la necesidad de apartar suficientes recursos mientras están trabajando. Otras quizás se nieguen a sabiendas a tomar medidas precautorias, ya que planean aprovechar la benevolencia gratuita del Estado, suponiendo que no se las dejará libradas a sus propios recursos en la vejez. Además de quienes recurren a estos argumentos que trasuntan miopía y riesgo moral, hay muchas personas que sencillamente no pueden ahorrar durante su vida activa debido, por ejemplo, a sus bajos ingresos, a la falta de acceso a mecanismos de ahorro, o al impacto negativo de acontecimientos externos que pueden haber barrido con todo ahorro acumulado. ${ }^{1}$ Siendo así, en general se acepta que los gobiernos deben establecer algún sistema de seguro social obligatorio. Por estos motivos, los sistemas de protección social fueron diseñados para otorgar cobertura en caso de enfermedad, discapacidad, vejez, maternidad y otras contingencias.

Los sistemas de protección social todavía conservan esas funciones fundamentales, pero con el tiempo también se les ha reconocido como instrumentos adecuados para redistribuir el ingreso entre los grupos de ingreso más alto y los de ingreso más bajo. ${ }^{2} \mathrm{~A}$ pesar del éxito inicial, los sistemas de reparto, en los cuales los gastos corrientes

\footnotetext{
$\square$ Este estudio fue elaborado durante el período en que el autor trabajaba en la sede subregional de la CEPAL para el Caribe (Puerto España, Trinidad y Tabago). Se agradecen los comentarios y sugerencias de un evaluador anónimo.

${ }^{1}$ Esto sucede principalmente en muchas economías rurales en desarrollo donde la riqueza es especialmente vulnerable a los desastres naturales, por ejemplo, en aquellas dedicadas a la ganadería.

${ }^{2}$ Si bien la expresión 'protección social' se suele referir a las prestaciones otorgadas para la vejez y en casos de enfermedad y discapacidad, en este artículo se aborda únicamente la función de proveer pensiones. Por esta razón, la expresión 'protección social' se refiere aquí a sistemas o planes de pensiones, a menos que se indique otra cosa. Ambas expresiones se usarán de manera indistinta.
}

se financian con las contribuciones corrientes, han sido objeto de un exhaustivo examen en los últimos años, dado que su sostenibilidad financiera es incierta, según indican las proyecciones demográficas. En particular, mientras que la esperanza de vida al nacer está aumentando en la mayor parte del mundo gracias al mejor acceso a los servicios de salud y los adelantos de la ciencia médica, los cambios de las pautas de conducta laborales no han cambiado a la par. En consecuencia, la porción de la vida que corresponde a la etapa de jubilación se ha acrecentado en relación con la correspondiente a la vida activa. Por esto y por la disminución de la fecundidad, muchos planes públicos de protección social corren el riesgo de sufrir un desequilibrio. ${ }^{3}$

Mientras el debate sobre la reforma de los sistemas de pensiones se está intensificando en muchos países, son numerosos los que ya han llevado a cabo reformas considerables. En América Latina, por ejemplo, 13 países han sancionado (o están en vías de sancionar) reformas estructurales que han consistido en reemplazar el sistema de reparto por uno de capitalización (como en Chile, la República Dominicana, El Salvador y México) o bien en introducir un sistema de capitalización en forma paralela al de reparto (como en Argentina, Colombia, Costa Rica, Perú y Uruguay). ${ }^{4,5}$ En el Caribe de habla inglesa, en cambio, en general no se han hecho reformas de importancia.

Una de las razones puede ser que, pese a la avalancha de investigaciones sobre los aspectos económicos de las pensiones que ha habido en los últimos treinta años, las conclusiones y las recomendaciones de política son de utilidad limitada para esta región de características geográficas y geoclimáticas peculiares, expuesta a desastres naturales y constituida íntegramente por pequeños Estados insulares en desarrollo.

\footnotetext{
${ }^{3}$ La diferencia entre sistemas de pensiones públicos y privados se analizará más adelante.

${ }^{4}$ En un plan de capitalización, el ingreso por concepto de contribuciones se invierte, de manera tal que cada generación financia casi por completo sus propias pensiones.

${ }^{5}$ Véase Gill, Packard y Yermo (2005). Obsérvese también que con la introducción de una reforma estructural no siempre se solucionan los problemas de sostenibilidad, como lo están descubriendo muchos países de América Latina.
} 
No obstante, la reforma de la protección social es especialmente necesaria en el Caribe porque allí puede reportar grandes beneficios. Si bien los sistemas nacionales de pensiones constituyen una parte importante de las respectivas economías, el hecho de que cada Estado caribeño tenga su propio plan limita las posibilidades de aprovechar las economías de escala. Más importante aún es que si bien la legislación actual restringe (en distintos grados) la inversión internacional de los fondos de reserva, la inversión conjunta en el extranjero podría reducir considerablemente los costos y fortalecer los sistemas de pensiones mediante una mayor diversificación. Aunque ya ha habido coordinación entre sistemas, lo que ha aumentado la portabilidad de las pensiones dentro de la región, si se quiere dar nuevo impulso a la integración regional es preciso reducir las restricciones a la movilidad de la mano de obra.

En este trabajo se procura ofrecer un panorama general de la protección social en el Caribe, para lo cual se presenta la estructura de los sistemas de protección social y se evalúan tanto sus resultados como las medidas de reforma adoptadas en cada caso. En la sección II siguiente se describe el estado actual de la protección social en la región analizada, en la sección III se reseñan los desafíos que enfrenta la protección social, en la sección IV se analizan opciones en materia de reforma y en la sección $\mathrm{V}$ se exponen las conclusiones.

\section{II}

\section{Protección social en el Caribe}

La protección social no es un fenómeno nuevo en el Caribe. ${ }^{6}$ Tras haberse extendido inicialmente desde Gran Bretaña en forma de fondos de previsión, la mayoría de los sistemas nacionales de protección social se implantaron poco después de la independencia. ${ }^{7} \mathrm{Si}$ bien solo Antigua y Barbuda y también Dominica establecieron sistemas nacionales de protección social antes de la independencia, el sistema nacional de protección social más antiguo de la región se puso en práctica en Jamaica en 1966, en tanto que los más nuevos fueron establecidos en 1987 en Saint Kitts y Nevis y en San Vicente y las Granadinas.

Sin embargo, en general los sistemas de protección social en el Caribe no se han modificado en gran medida desde entonces. Salvo cambios de parámetros efectuados a intervalos irregulares no se ha efectuado reforma real alguna y hay pocos indicios de que se esté estudiando una reforma importante, debido a di-

\footnotetext{
${ }^{6}$ En este trabajo se entiende por "el Caribe" o "la región" el conjunto de los miembros de habla inglesa del Comité de Desarrollo y Cooperación del Caribe (CDCC) más Suriname; se excluyen los miembros asociados, a menos que se indique otra cosa. Los miembros plenos son Antigua y Barbuda, Bahamas, Barbados, Belice, Dominica, Granada, Guyana, Jamaica, Saint Kitts y Nevis, Santa Lucía, San Vicente y las Granadinas, Suriname y Trinidad y Tabago.

${ }^{7}$ A fines de los años 1960 y comienzos de los años 1970 se establecieron diversos regímenes de protección social basados en las ocupaciones, que cubrían algunos sectores de las economías. Más adelante fueron reemplazados por los sistemas nacionales de protección creados recientemente.
}

versos factores que se examinarán en este estudio. Un motivo de la falta de interés por reformar los sistemas de pensiones en la región puede ser que, por haberse establecido hace relativamente poco tiempo, los planes nacionales de seguros aún no han alcanzado la etapa de madurez. Esto se refleja en la baja tasa de dependencia ancianos/personas activas y en los reducidos pagos de la protección social, que ascienden en promedio al $2 \%$ del PIB en la región (tasa significativamente inferior a la de otras regiones). Además, a lo largo de los años todos los sistemas han logrado acumular reservas bastante cuantiosas, que equivalen a aproximadamente el 19\% del PIB regional y que en algunos países llegan a ser de hasta el 30\% del PIB nacional.

Con todo, dichas reservas deberían considerarse como una oportunidad para enfrentar el problema de la sostenibilidad de la protección social antes de que este se agrave.

Para entender estos desafíos hay que saber cómo funciona la protección social en la región y qué parámetros determinan sus resultados. Habida cuenta del número de países involucrados, el análisis de los sistemas de los Estados miembros en su conjunto siempre implicará sacrificar detalles. Sin mucha pérdida de generalidad, en esta sección se presenta un panorama global de la protección social en el Caribe y se explica cómo están estructurados los sistemas de pensiones, qué contribuciones se imponen y cómo se calculan las prestaciones. También se consignan los costos en que 
GRÁFICO 1

El Caribe: tasa de contribución a la protección social, 2003

(Porcentajes)

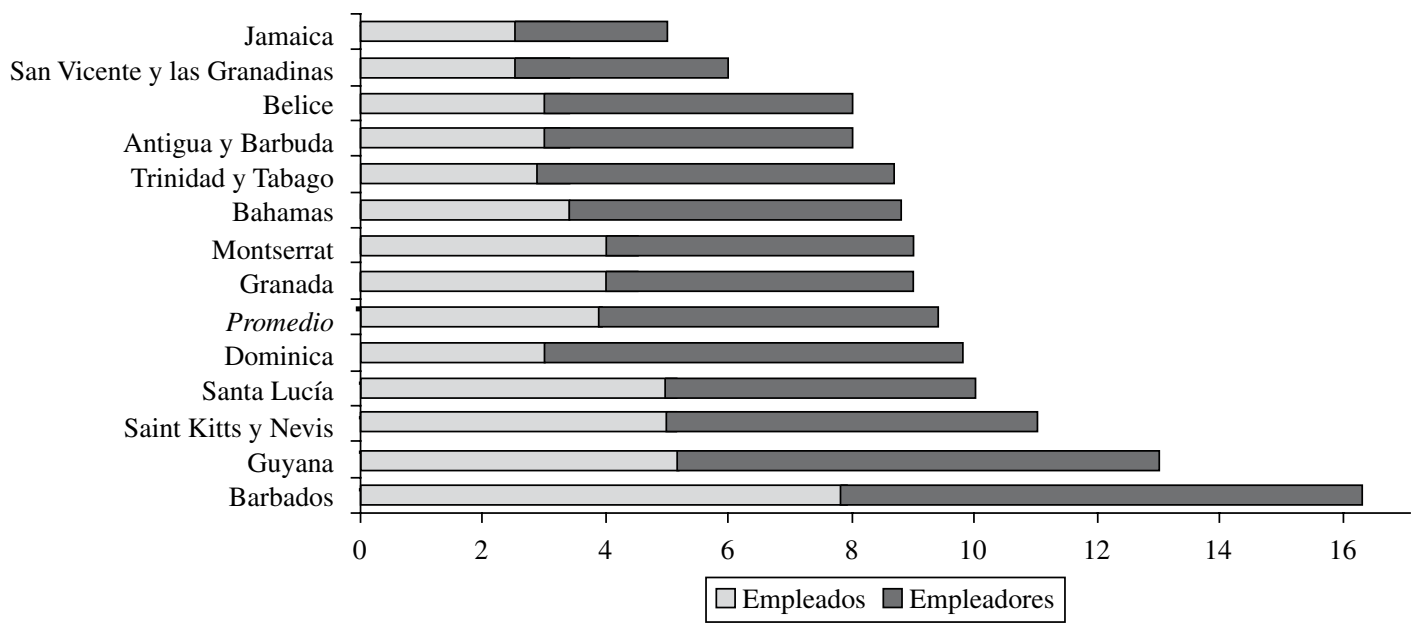

Fuente: datos oficiales.

están incurriendo las juntas nacionales de protección social y se describe cómo se invierten en la actualidad los excedentes.

\section{Contribuciones y prestaciones}

\section{a) Contribuciones}

Todos los esquemas públicos de protección social en la región son sistemas de reparto con prestaciones definidas. ${ }^{8}$ Se caracterizan por establecer parámetros relativos a la manera en que se generan los ingresos y se calculan las prestaciones (pensiones). Los dos principales parámetros que definen la generación de ingresos de los fondos de pensiones son la tasa de contribución y el tope al salario imponible (el nivel salarial por encima del cual ya no se imponen contribuciones).

Las prestaciones se financian con las contribuciones de empleados y empleadores expresadas como porcentaje de los salarios de los empleados. En el Caribe estas tasas son en promedio de $4 \%$ y $6,8 \%$, respectivamente. Sin embargo, varían mucho de un país a otro (gráfico 1): las tasas más altas para empleados y empleadores corres-

\footnotetext{
${ }^{8}$ En los planes de prestaciones definidas, las contribuciones son endógenas al sistema y varían para equilibrar el presupuesto de pensiones, puesto que las prestaciones son definidas a priori. En cambio, en los planes de contribuciones definidas las prestaciones son determinadas en forma endógena por las contribuciones.
}

ponden a Barbados $(7,75 \%$ y $8,5 \%$, respectivamente $)$ y las más bajas a Jamaica (2,5\% para unos y otros). ${ }^{9}$

Además de variar las tasas de contribución, también varían mucho los topes a los salarios imponibles, que oscilan entre un promedio de 1,2 veces los salarios medios imponibles en Trinidad y Tabago y 3,4 veces en Santa Lucía. ${ }^{10}$ En general, no hay un tope salarial 'ideal' para las contribuciones; es más, varios países han eliminado toda clase de topes en los últimos procesos de reforma. ${ }^{11}$ La ventaja de fijar un tope salarial elevado consiste en que serán menos las personas que deberán ahorrar por su cuenta para aminorar los altibajos de su consumo a lo largo de la vida ante el aumento de la porción de sus ingresos que queda por encima del tope y que, por lo tanto, no es imponible. En tales casos, los mercados de capital bien desarrollados o los regímenes de pensiones de carácter ocupacional y con una base amplia pueden cubrir la brecha y evitar las fuertes variaciones del

\footnotetext{
${ }^{9}$ Sin embargo, estas tasas son relativamente más bajas que las impuestas en los sistemas obligatorios de América Latina, las que van desde el 2,75\% en Argentina al 12,27\% en Uruguay (Gill, Packard y Yermo, 2005).

${ }^{10}$ Para tener un denominador común, los topes de ingresos se han normalizado utilizando los salarios medios imponibles en lugar de los salarios medios nacionales, para los que no se dispone de datos en la mayoría de los países.

${ }^{11}$ En varios países de Europa central y oriental (como la República Checa, Estonia, Eslovenia) no existen topes para las contribuciones a los planes de pensiones (Unión Europea 2002). Tampoco existen en Portugal, Austria y Finlandia (Unión Europea 2006).
} 
consumo que se producen cuando los topes son bajos. Sin embargo, la disponibilidad de unos y otros en el Caribe es limitada, lo que refuerza los argumentos en favor de topes más altos.

Además, salvo Guyana, todos los Estados miembros ajustan sus topes según las circunstancias, en lugar de valerse de un mecanismo automático. ${ }^{12}$ Asimismo, los ajustes se efectúan a intervalos infrecuentes: así, el tope salarial solo se ha ajustado dos veces en tres decenios en Bahamas, tres veces en dos décadas en las Islas Vírgenes Británicas, y en las Islas Turcas y Caicos no ha subido desde la creación del esquema de pensiones en 1992. En consecuencia, cuando se producen aumentos, suelen ser considerables, como lo ilustra el caso de Belice: en 2001 el tope de ingresos imponibles se elevó por primera vez desde que se estableció el sistema en 1979, y pasó de130 a 320 dólares de Belice por semana. Este tope aún no se considera lo suficientemente alto, de modo que el gobierno está estudiando la posibilidad de llevarlo a 640 dólares de Belice por semana en el futuro cercano, de conformidad con lo recomendado en la sexta revisión actuarial del esquema de protección social (Montas, 2003). Es preciso fijar topes adecuados, principalmente porque de ser bajos conspiran contra la progresividad de los planes, ya que las personas de ingresos altos solo pagan una contribución baja en relación con sus ingresos.

\section{b) Prestaciones}

Las prestaciones de la protección social son en gran medida de naturaleza uniforme en toda la región. En principio, son prestaciones por enfermedad, maternidad, jubilación, invalidez, así como también pensiones por sobrevivencia y asignaciones mortuorias. Mientras que varios países ofrecen prestaciones relacionadas con accidentes de trabajo y enfermedades profesionales (como pensiones por discapacidad, prestaciones en caso de accidentes de trabajo y enfermedades profesionales y cobertura de gastos médicos), únicamente Barbados otorga indemnizaciones por desempleo. Sin embargo, como ya se señaló, en el presente estudio el análisis de la protección social se limita a la función de los sistemas de pensiones.

El objetivo primordial de tales sistemas en la región es el de mantener un ingreso en la vejez y la discapacidad. Esto se confirma por el hecho de que todos los planes

\footnotetext{
${ }^{12}$ En Guyana el tope a los ingresos imponibles (y las pensiones) se ajusta de acuerdo con la variación del salario mínimo del sector público.
}

de reparto de la región son proporcionales a los ingresos y, por lo tanto, se basan en el principio de protección social de mantener las mismas condiciones durante la vejez. Sin embargo, la eficacia de los sistemas destinados a asegurar ingresos a las personas mayores varía dentro de la región, especialmente respecto al número de personas que perciben jubilaciones. Así, se estima que la proporción de personas mayores de 65 años que reciben jubilaciones oscila entre un mínimo de $19 \%$ en Santa Lucía y un máximo de $85 \%$ en Barbados; en las economías más grandes, como Jamaica, Bahamas y Trinidad y Tabago, los porcentajes respectivos son aproximadamente de $38,6 \%, 53 \%$ y $56,8 \% .{ }^{13}$ Uno de los factores que explican la baja cobertura en algunos países es el hecho de que las tasas de cumplimiento en materia de contribuciones en el caso de los trabajadores independientes son bajas y el sector informal de muchas economías es bastante grande. Además, la elevada tasa de desempleo y el hecho de que todos los sistemas sean de reparto y financiados por contribuciones, implica que muchas personas que llegan a la vejez tal vez no reúnan los requisitos para pensionarse. Sin embargo, las cifras revelan que la cobertura ha ido aumentando paulatinamente, aunque a un ritmo moderado (por ejemplo, en en el año 2000 la cobertura en Bahamas y Santa Lucía fue de $45,2 \%$ y $15,9 \%$, respectivamente).

La generosidad de los sistemas basados en los ingresos se mide por la tasa de sustitución de ingresos al jubilar. La posición de los distintos países frente a esta tasa es bastante uniforme, aunque las reglas sobre la acumulación individual varían en alguna medida de un país a otro: en la mayoría de los planes de pensiones la tasa de sustitución es del $30 \%$ de las contribuciones efectuadas en aproximadamente 10 años (más precisamente, en 500 semanas). Antigua y Barbuda exhiben la tasa de reemplazo más baja, del 25\%, y Barbados la más generosa, del orden del 40\%. En general, en todos los sistemas de la región las tasas de sustitución aumentan relativamente más en los primeros años de contribución que en los últimos. Después de un período de contribución de 30 años (1.500 semanas) llegan a entre el 50\% y el 55\%; los extremos se registran en Barbados (60\%) y Antigua y Barbuda (45\%). En lo que se refiere a las tasas máximas de reemplazo, Dominica tiene la tasa más alta

\footnotetext{
${ }^{13}$ En este caso la cobertura mide el número de prestaciones de larga duración otorgadas (excluidas las prestaciones por sobrevivencia y por discapacidad) en relación con el tamaño de la población de más de 65 años. En los países donde la edad de jubilación es inferior a los 65 años, como Santa Lucía (véase el cuadro 1), la cobertura del grupo etario pertinente real será necesariamente menor.
} 
El Caribe: estadísticas de la protección social, 2003

\begin{tabular}{|c|c|c|c|c|c|c|c|c|c|}
\hline & \multirow[t]{2}{*}{$\begin{array}{l}\text { Ingresos } \\
\text { máximos } \\
\text { imponibles }\end{array}$} & \multicolumn{2}{|c|}{$\begin{array}{l}\text { Relación } \\
\text { pensiones/salarios } \\
\text { medios imponibles }\end{array}$} & \multicolumn{3}{|c|}{$\begin{array}{c}\text { Tasa de sustitución } \\
\text { de los ingresos al jubilar (\%) } \\
\text { (Después de ... años) }\end{array}$} & \multirow{2}{*}{$\begin{array}{c}\text { Contribución } \\
\text { mínima }\end{array}$} & \multicolumn{2}{|c|}{$\begin{array}{c}\text { Edad de } \\
\text { jubilación }\end{array}$} \\
\hline & & $\begin{array}{c}\text { Media } \\
(\%)\end{array}$ & $\begin{array}{l}\text { Mínima } \\
(\%)\end{array}$ & 10 & 30 & Máxima & & Normal & Anticipada \\
\hline Columna & & (1) & (2) & (3) & (4) & (5) & (6) & (7) & (8) \\
\hline Anguilla & 2,02 & 30,6 & 26,3 & 30 & 50 & 60 & 250 & 65 & $\ldots$ \\
\hline Antigua y Barbuda & 1,88 & 22,2 & 6,3 & 25 & 45 & 50 & 350 & 60 & $\ldots$ \\
\hline Bahamas & 1,36 & 25,4 & 16,0 & 30 & 55 & 60 & 150 & 65 & 60 \\
\hline Barbados & 2,09 & 49,0 & 30,6 & 40 & 60 & 60 & 500 & 65 & 63 \\
\hline Belice & 1,52 & 25,3 & 22,4 & 30 & 55 & 60 & 500 & 65 & 60 \\
\hline Islas Vírgenes Británicas & 1,42 & 21,4 & 7,5 & 30 & 50 & 60 & 500 & 65 & $\ldots$ \\
\hline Dominica & 3,15 & 28,3 & 6,8 & 30 & 55 & 70 & 500 & 60 & $\ldots$ \\
\hline Granada & 2,07 & 24,5 & 12,0 & 30 & 50 & 60 & $400^{\mathrm{a}}$ & 60 & $\ldots$ \\
\hline Guyana & 2,1 & 28,5 & 27,3 & $40^{\mathrm{b}}$ & 55 & 60 & 750 & 60 & $\ldots$ \\
\hline Jamaica & & & & $\mathrm{c}$ & & & 494 & $70^{\mathrm{d}}$ & $65^{\mathrm{d}}$ \\
\hline Montserrat & 1,26 & 17,1 & 8,4 & 30 & 50 & 60 & $350^{\mathrm{e}}$ & 60 & $\ldots$ \\
\hline Saint Kitts y Nevis & 3,07 & 28,4 & 11,8 & 30 & 55 & 60 & 500 & 62 & $\ldots$ \\
\hline Santa Lucía & 3,41 & 39,0 & 13,7 & & 58 & 60 & $576^{f}$ & 61 & 60 \\
\hline San Vicente y las Granadinas & 3,08 & 29,9 & 19,4 & 30 & 50 & 60 & $325^{\mathrm{e}}$ & 60 & $\ldots$ \\
\hline Trinidad y Tabago & 1,25 & 37,0 & 37,0 & $\mathrm{~g}$ & & & 750 & 65 & 60 \\
\hline Islas Turcas y Caicos & 1,69 & 19,0 & 14,1 & 30 & 55 & 60 & 500 & 65 & 60 \\
\hline Promedios & 2,1 & 27,0 & 17,3 & 33,5 & 53,1 & 60 & 432 & 63 & 61 \\
\hline
\end{tabular}

Fuente: datos oficiales y Osborne (2004).

a Con aumento a 500 en 2008.

b Después de 15 años.

c Pensiones basadas en una tasa uniforme más una proporción relacionada con los ingresos.

d Cinco años menos en el caso de las mujeres.

e Con aumento a 500 en etapas anuales de 25 .

f 144 meses, con aumentos de 12 meses cada tres años hasta llegar a 180 el $1^{\circ}$ de enero del 2012.

g Pensiones basadas en un grupo promedio con contribuciones a lo largo de toda su vida activa (método de ingresos durante la vida activa, sin indexación).

que puede lograrse, del 70\%, y Antigua y Barbuda tiene el límite máximo más bajo, del 50\% (cuadro 1).

Son discutibles los méritos de un aumento no lineal de la tasa de sustitución. Por ejemplo, es útil en las etapas iniciales de un plan de pensiones, ya que permite a los miembros reunir rápidamente las condiciones para obtener una pensión más alta. En tal caso, una vez establecido, el plan puede ser de gran utilidad para los trabajadores de más edad. Sin embargo, en general una fórmula más lineal de cálculo de las prestaciones reducirá el costo total de las jubilaciones, puesto que los que se jubilen antes recibirán prestaciones más bajas. Al respecto, en Belice se está pensando en reemplazar la fórmula actual —un aumento del 3\% durante los primeros 10 años de contribución al plan, seguido de un aumento anual del $2 \%$ durante los cinco años siguientes y de $1 \%$ cada año posterior-, por un aumento anual uniforme del 1,5\% de la tasa de reemplazo hasta un máximo de $60 \%$, que se alcanzaría después de 40 años de contribuciones (Montas, 2003). En la revisión actuarial del 2003 correspondiente a Santa Lucía también se recomendó modificar la tasa de acumulación de las pensiones, de modo de tornarla más paulatina que en la actualidad.

Las tasas de sustitución representan tan solo uno de los aspectos del cálculo de las pensiones. Otros son los ingresos medios imponibles a los que se aplican estas tasas, la forma en que esos ingresos se calculan y los requisitos para pensionarse.

Los ingresos medios imponibles por lo general se calculan tomando el promedio de los mejores 3 a 5 años de los últimos 10 a 15 años de trabajo de cada persona. ${ }^{14}$

\footnotetext{
${ }^{14}$ Las excepciones son Barbados, Trinidad y Tabago y Jamaica. En Trinidad y Tabago las pensiones se basan en el promedio de ingresos obtenidos durante la vida activa según 'clases de ingresos' (grupos
} 
Sin embargo, es probable que calcular las prestaciones de esa manera, en lugar de basar los pagos de pensiones en un historial completo de ingresos, contribuya a la regresividad del plan, pues favorece a los trabajadores más calificados que se incorporan más tarde a la fuerza de trabajo pero a la vez perciben salarios más altos y crecientes que los trabajadores menos calificados, cuyos ingresos son relativamente uniformes. Por ejemplo, en Bahamas se está estudiando la posibilidad de pasar a un sistema en el que se reemplace la fórmula de cálculo de las pensiones según la remuneración media de los últimos tres años, por uno en el cual las pensiones se basen en un sistema de ingresos indexados obtenidos durante la vida activa, con una tasa anual de acumulación del 1,5\%.

\section{c) Requisitos para jubilarse}

En todos los Estados miembros la edad normal de jubilación varía entre los 60 y los 65 años, salvo en Jamaica, donde la edad normal de jubilación (de los hombres) se ha fijado en los 70 años. Aunque no existen requisitos de residencia o ciudadanía para obtener una pensión, sí se exige un número mínimo de contribuciones. Muchos países han fijado en 500 semanas el número mínimo necesario para obtener una pensión completa. En Santa Lucía los trabajadores deben hacer contribuciones durante 12 años (144 meses). En Guyana y en Trinidad y Tabago se requiere haber efectuado aportes, como mínimo, durante 15 años (750 semanas de contribuciones) para poder recibir una pensión. En cambio, en Montserrat y en San Vicente y las Granadinas solo se exigen 7 años y 6,5 años, respectivamente; en Anguilla se requieren apenas cinco años, y en Bahamas, para tener derecho a pensión tan solo se necesitan tres años (150 semanas) de contribuciones al plan nacional de pensiones, con una tasa de reemplazo del $15 \%$ de los ingresos medios imponibles.

En general, a los trabajadores que no reúnen el número mínimo exigido de contribuciones se les garantiza una pensión mínima, la que varía considerablemente en toda la región: entre el 6\% de los salarios medios imponibles en Antigua y Barbuda y el $31 \%$ en Barbados (cuadro 1).

de ingresos); en Barbados las pensiones tienen dos niveles, con una pensión 'básica' igual al $40 \%$ de los ingresos medios imponibles (sobre la base de los mejores cinco años de remuneración) y una pensión complementaria igual al 1\% del total de ingresos semanales imponibles representados por las contribuciones que exceden de las primeras 500 semanas; Jamaica también tiene un sistema de dos niveles.
Varios países de la región han tomado medidas para abordar el hecho de que un número relativamente pequeño de contribuciones baste para acceder a una pensión. Este asunto es importante, no solo porque en un entorno cada vez más globalizado la movilidad de la mano de obra va en aumento, sino también porque, con el tiempo, el Mercado Económico Único del Caribe permitirá la libre movilidad dentro de la región, lo que podría conducir a que los trabajadores "vitrinearan pensiones" antes de elegir lugar de trabajo. En este sentido, en Montserrat y San Vicente y las Granadinas se está elevando anualmente el número exigido de contribuciones semanales - de a 25 por vez-, para llegar a un total de 500. En Granada el número exigido se elevará a 500 para el año 2008 y en Santa Lucía se están agregando 12 meses cada tres años a fin de alcanzar un total de 180 meses de contribuciones en el año 2012. En otros Estados miembros ya se ha empezado a estudiar cómo encarar este problema. En Bahamas, la Comisión de reforma de la protección social ha recomendado que el número de contribuciones semanales se incremente anualmente - 50 por vez - hasta que el número exigido se ajuste más al vigente en la región, es decir, hasta que se llegue a las 500 contribuciones.

\section{Costos e inversiones}

El éxito de los planes de protección social puede medirse atendiendo a varios aspectos. Un aspecto importante es el costo de administración del plan, que abarca, por ejemplo, el financiamiento de las instituciones administradoras, el pago de los salarios de su personal, el mantenimiento de las instalaciones y la prestación de los servicios que se esperan de las instituciones.

Dentro de la región, los costos de operación difieren considerablemente. En promedio ascienden al 18\% del ingreso de los sistemas de pensiones por concepto de contribuciones, pero por país revelan una variación significativa, siendo el porcentaje más elevado el de Montserrat (41\%) y el más bajo el de Barbados (6\%). En general, la cuarta parte de los países de la muestra registra más de una desviación típica de la media. Es más, mientras que solo Barbados y Trinidad y Tabago tienen gastos de operación inferiores al 10\% del ingreso por concepto de contribuciones, en Anguilla, Belice, Montserrat y las Islas Turcas y Caicos esos gastos superan el 20\% (cuadro 2).

Este nivel de costos es evidentemente demasiado alto para los planes de reparto y también si se le compara, por ejemplo, con el de $0,5 \%$, aproximadamente, que corresponde al ingreso por concepto de contribuciones 


\begin{tabular}{|c|c|c|c|}
\hline País & Gastos $(\%)$ & País & Gastos (\%) \\
\hline Anguilla ${ }^{\mathrm{a}}$ & 22,8 & Guyana & 15,8 \\
\hline Antigua y Barbuda ${ }^{a}$ & 17,7 & Jamaica & 13,0 \\
\hline Bahamas & 19,9 & Montserrat $^{\mathrm{a}}$ & 48,8 \\
\hline Barbados & 6,1 & Saint Kitts y Nevis ${ }^{a}$ & 14,6 \\
\hline Belice & 30,5 & Santa Lucía & 13,3 \\
\hline Islas Vírgenes Británicas ${ }^{\mathrm{a}}$ & 11,9 & San Vicente y las Granadinas ${ }^{\mathrm{a}}$ & 16,7 \\
\hline Dominica $^{\mathrm{a}}$ & 16,7 & Trinidad y Tabago $^{\mathrm{a}}$ & 7,1 \\
\hline Granada $^{\mathrm{a}}$ & 12,4 & Islas Turcas y Caicos & 21,1 \\
\hline
\end{tabular}

Fuente: datos oficiales y Osborne (2004).

a Las cifras corresponden al año 2005.

del plan de reparto administrado por el sector público en los Estados Unidos. ${ }^{15}$ No es de sorprender que las características geográficas de la región influyan en los gastos generales de operación: el coeficiente de correlación entre la población de cada país y los gastos operativos del plan de protección social es significativo y negativo $(-0,47)$, lo que indica que los sistemas de protección social no tienen capacidad para aprovechar las economías de escala. En especial, las economías insulares, como Bahamas y las Islas Turcas y Caicos, exhiben costos proporcionalmente más altos. ${ }^{16}$ Indudablemente, los costos son altos debido a la incapacidad para aprovechar las economías de escala.

\section{a) Excedentes}

Con todo, los sistemas de protección social otorgan pensiones a más de 250.000 de los 6.500 .000 habitantes de la región. El total de contribuciones a los planes fue de aproximadamente 650 millones de dólares, suma muy superior a los 450 millones pagados por estos sistemas en pensiones y otras prestaciones en el 2003 y que se tradujo en un aumento de las reservas. Este rasgo, por cierto, ha sido característico de la región caribeña, que a fines del 2003 había acumulado fondos por más de 5.200 millones de dólares: esta suma se aproximaba al $19 \%$ del PIB regional, o alrededor del 30,1\% del PIB de algunos países. Es más, la posición financiera de los planes de pensiones de la región podía considerarse buena. De hecho, pese a que todos esos planes son de

\footnotetext{
15 Véase Thompson (2001, p. 242).

${ }^{16}$ Sin embargo, al parecer en Belice, economía no insular que no es particularmente pequeña frente a otros países de la región, también se registran costos extraordinariamente altos.
}

reparto, las reservas que han acumulado superan a los activos de los planes de capitalización en cada uno de los países de América Latina (excepto Chile). En América Latina los activos ascendieron, en promedio, a alrededor del 13,5\% del PIB (Gill, Packard y Yermo, 2005). Asimismo, hoy todos los sistemas de pensiones están acumulando excedentes, lo que es bueno ya que si bien por definición todos son planes de reparto, las reservas acumuladas pueden utilizarse en el futuro para cubrir insuficiencias imprevistas de contribuciones o aumento de los compromisos.

Las reservas tienen una correlación negativa $(-0,62)$ con el tamaño del país. La proporción más baja se observa en Jamaica, en tanto que las reservas representan más de las dos terceras partes del PIB de Saint Kitts y Nevis (gráfico 2). Sin embargo, la magnitud total de las reservas acumuladas no es indicador de la sostenibilidad de un plan desde el punto de vista financiero, puesto que no mide aspecto alguno del desempeño ni señala por cuánto tiempo las reservas podrán cubrir los compromisos. Por ello, un indicador más útil es la relación reservas/gastos, que permite obtener una aproximación de cuántos gastos anuales podrían financiarse con las reservas. Estos valores, como se observa en el gráfico 2, revelan una historia algo diferente, ya que parece no haber una relación directa entre las reservas acumuladas, medidas como porcentaje del PIB, y el monto de gastos anuales que podría cubrirse con ellas. De hecho, en los estudios actuariales se ha señalado la necesidad de tomar medidas para evitar el agotamiento de los fondos. Dada la situación actual, se ha estimado, por ejemplo, que en el 2019 los gastos en Bahamas serán superiores a los ingresos, lo que conducirá al agotamiento del fondo en 
GRÁFICO 2

EI Caribe: reservas y relación reservas/gastos, 2003

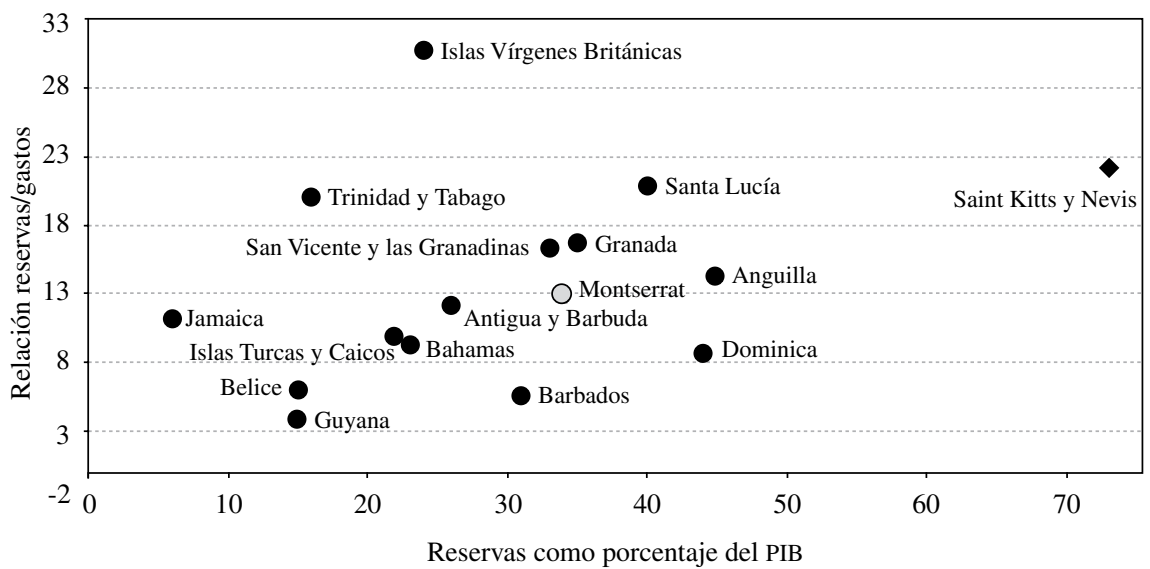

Fuente: datos oficiales y Osborne (2004).

2029. Asimismo, el fondo de reserva de Belice tal vez se agote un poco antes (en 2025) en las condiciones actuales. De igual manera, se prevé que en 2048 las reservas comenzarán a disminuir en Santa Lucía y, según las proyecciones, se agotarán en 2062. ${ }^{17}$

\section{b) Inversiones de cartera}

Una gran proporción de las reservas acumuladas se invierte ( $89 \%$ en promedio). Antigua y Barbuda es el único país donde la tasa de inversión, de $44 \%$, es inferior al 75\%. ${ }^{18}$ En consecuencia, la gestión de la cartera es un aspecto importante de los planes regionales de protección social y debe analizarse detenidamente.

La gestión de la cartera de los diversos planes en el último decenio no ha sido sobresaliente: la rentabilidad media real fue de alrededor de 3,8\%, si bien en los últimos cinco años aumentó ligeramente hasta situarse cerca del 4,2\%. Belice y Jamaica obtuvieron resultados considerablemente mejores que el promedio: en Belice el rendimiento en 10 años y 5 años fue del $7,4 \%$ y $7,5 \%$, respectivamente, y en Jamaica el rendimiento en cinco años ascendió al 9,8\%. El desempeño de Antigua y Barbuda, Anguilla y las Islas Turcas y Caicos fue significativamente inferior al promedio: el rendimiento de Antigua en 10 y 5 años fue de $0,8 \%$ y $1,5 \%$, respectivamente, el de las Islas Turcas y Caicos

\footnotetext{
${ }^{17}$ Véase National Insurance Board of the Bahamas (2001), Montas (2003) y OIT (2005).

${ }^{18} \mathrm{Sin}$ embargo, esto se debe al monto considerable de deudas por cobrar, que asciende a la mitad del total de activos.
}

fue de $1,6 \%$ y de $0,9 \%$, y el de Anguilla en 5 años fue de $1,5 \%$ (cuadro 3 ). ${ }^{19}$

Una de las razones de dicho desempeño deficiente es, sin lugar a dudas, la manera en que se asignan estas inversiones. Aproximadamente la mitad del total de reservas se invierte en títulos de renta fija (como préstamos y bonos) y la tercera parte en depósitos a plazo fijo. Se trata de instrumentos de inversión que históricamente son bastante estables, pero también de bajo rendimiento. En total, sólo el $11 \%$ de las reservas se invierte en acciones y el $4 \%$ en bienes inmuebles (porcentajes correspondientes a fines de 2003).

La mayoría de los países tiene carteras con un marcado sesgo hacia las inversiones locales. En verdad, solo los territorios no independientes (Anguilla, Islas Vírgenes Británicas, Montserrat y las Islas Turcas y Caicos) tienen más del 5\% de sus activos invertidos en el extranjero. En las Islas Vírgenes Británicas, esa proporción es de más de las dos terceras partes del total de inversiones y en las Islas Turcas y Caicos supera las tres cuartas partes. Seis países han hecho exclusivamente inversiones nacionales, entre ellos las economías más grandes: Trinidad y Tabago, Jamaica, Bahamas y Belice. Sólo siete países han realizado inversiones regionales, que en cada caso fueron inferiores al $10 \%$ del total de inversiones, salvo en el caso de San

\footnotetext{
${ }^{19}$ Los rendimientos se estiman 'considerablemente peores o mejores' si registran más de una desviación estándar por debajo o por encima, respectivamente, del promedio regional.
} 


\begin{tabular}{lccc}
\hline & $\begin{array}{c}\text { Rentabilidad } \\
\text { real, 10 años } \\
(\%)\end{array}$ & $\begin{array}{c}\text { Rentabilidad } \\
\text { real, 5 años } \\
(\%)\end{array}$ & $\begin{array}{c}\text { Inversiones } \\
\text { como } \% \text { de } \\
\text { las reservas }\end{array}$ \\
\hline Anguilla & 2,50 & 1,50 & 91,80 \\
Antigua y Barbuda & 0,80 & 1,50 & 44,40 \\
Bahamas & 4,80 & 4,00 & 92,40 \\
Barbados & 5,20 & 5,20 & 82,40 \\
Belice & 7,40 & 7,50 & 94,50 \\
Islas Vírgenes Británicas & 2,20 & 2,80 & 92,80 \\
Dominica & 4,70 & 4,60 & 77,00 \\
Granada & 5,00 & 4,90 & 92,10 \\
Guyana & 4,80 & 4,10 & 95,30 \\
Jamaica & 3,50 & 9,80 & 95,50 \\
Montserrat & 2,40 & 2,40 & 96,70 \\
Saint Kitts y Nevis & 3,20 & 4,00 & 94,90 \\
Santa Lucía & 3,80 & 4,10 & 96,00 \\
San Vicente y las Granadinas & 4,30 & 5,60 & 91,60 \\
Trinidad y Tabago & 4,70 & 4,70 & 93,40 \\
Islas Turcas y Caicos & 1,60 & 0,90 & 87,50 \\
Promedio no ponderado & 3,81 & 4,23 & \\
\hline
\end{tabular}

Fuente: datos oficiales y Osborne (2004).

Vicente y las Granadinas, donde la quinta parte de las inversiones son regionales.

Las razones de tanta concentración de las carteras de inversiones son fundamentalmente dos. En primer lugar, la legislación de muchos Estados miembros no permite invertir los fondos de la protección social en el extranjero. En un gran número de países se considera que la protección social es un instrumento necesario para suministrar fondos a la economía. Asimismo, son muchos quienes estiman en la región que a las organizaciones de protección social les cabe una importante función en el desarrollo económico: más de la mitad de los encuestados en la Organización de los Estados del
Caribe Oriental (OECO) expusieron esta opinión (Henry, 2004, p. 194). Sin embargo, en el mismo estudio también se concluyó que más del $70 \%$ de los encuestados consideró necesario diversificar las carteras mediante inversiones extranjeras y señaló la necesidad de modificar la legislación. En segundo lugar, el citado desequilibrio de las inversiones - sobre todo en lo que respecta a la concentración en depósitos a plazo fijo- obedece también a que los mercados de capital de la región son más bien incipientes: solo existen tres mercados de valores regionales, y en cada uno de ellos se cotizan pocos títulos. ${ }^{20}$ Por ello, toda diversificación de cartera es una tarea difícil y compleja.

\section{III \\ Desafíos que encara la protección social en el Caribe}

En 1994 el Banco Mundial publicó un informe sobre la protección social que hablaba del "envejecimiento sin crisis" (Banco Mundial, 1994). Esta fue una de las primeras publicaciones de una organización internacional en que se abogaba por una política de pensiones basada en múltiples pilares. En ese informe se propugna el esta- blecimiento de tres pilares principales para financiar la protección social. El primer pilar se basa en el principio

\footnotetext{
${ }^{20}$ En la Bolsa de Valores del Caribe Oriental cotizan ocho títulos; en las bolsas de valores de Jamaica y de Trinidad y Tabago cotizan, respectivamente, menos de 50 títulos.
} 
de reparto. El segundo pilar es el de capitalización: los trabajadores efectúan contribuciones obligatorias en cuentas personales, estas contribuciones se invierten y con el tiempo se utilizan para financiar las pensiones de esos mismos trabajadores; la participación en este pilar ha de ser obligatoria. Por último, el tercer pilar apunta a promover el ahorro; es, en esencia, similar al segundo, con la única diferencia de que las contribuciones son voluntarias (es decir, este pilar se equipara al ahorro privado).

Si bien el informe señalado no ha estado exento de críticas, ${ }^{21}$ tuvo una profunda influencia en varios países en desarrollo — especialmente de América Latina, donde se ha sancionado un cúmulo de reformas en los últimos dos decenios- y sigue siendo influyente en muchas regiones. En verdad, son cada vez más las economías que están abandonando el plan de reparto tradicional con prestaciones definidas; esto se debe en parte a la dinámica de la población, pero también al hecho de que los planes de reparto aumentan el incentivo para acogerse a jubilación anticipada, lo que contribuye a crear una situación insostenible en términos de financiamiento (Gruber y Wise, 1999).

Sin embargo, esa dinámica parece haber tenido escasos efectos en la agenda de protección social del Caribe: los planes nacionales son representativos del primer pilar únicamente. Si bien todos estos esquemas presentan diferencias en materia de derechos a prestaciones, tasas de contribución y otros parámetros, están diseñados en principio como planes de reparto. En ese sentido no existe un segundo pilar obligatorio en la región ni se observa indicación clara alguna de que se vaya a establecer.

La falta de interés en la reforma puede obedecer a la actual coyuntura demográfica, es decir, al hecho de que las poblaciones son relativamente jóvenes y a que los planes de protección social son recientes. Por lo tanto, los planes nacionales de protección social de la región aún no han alcanzado la etapa de madurez (los planes menos maduros tienen una proporción más alta de miembros activos que de miembros jubilados o con jubilaciones diferidas) y por ende están recibiendo contribuciones más que suficientes para financiar sus obligaciones actuales. Todos ellos se encuentran entonces en condiciones de invertir ('capitalizar') los recursos excedentes.

Aunque en el Caribe el problema del envejecimiento no es tan acuciante como en otras regiones, es menester abordarlo, ya que la experiencia demuestra que cuanto más pronto se aborde, tanto menos penosas

${ }^{21}$ Véase, por ejemplo, Orszag y Stiglitz (2001). serán las soluciones y tanto menor el costo político de aplicarlas. En verdad, la protección social en la región encara varios desafíos. Algunos de ellos tienen que ver con aspectos de los planes actuales, como la forma de calcular las prestaciones, el bajo número de contribuciones exigidas para acceder a las prestaciones, la falta de ajuste automático de los topes salariales y las tasas de reemplazo de los salarios. Estos retos (que en lo que correspondía se señalaron en la sección anterior) pueden afrontarse cambiando los parámetros y modificando la legislación vigente.

Otros desafíos, sin embargo, revisten más importancia para la protección social y deben analizarse en mayor detalle. Uno se refiere a los mercados de trabajo, y en especial al Mercado Económico Único del Caribe, que a la postre llevará a la libre movilidad de la mano de obra e incidirá en la protección social. Otro es el desempeño general de los mercados de trabajo de la región: en algunos países la tasa de desempleo es alta y persistente, el sector informal está creciendo y se ha generalizado la evasión de las contribuciones a los sistemas de protección social. Estos factores conducirán en definitiva a que una proporción creciente de las personas mayores quede excluida de los beneficios de una pensión, y por lo tanto, deben abordarse.

También es preciso modificar la legislación aplicable a la acumulación de activos de la protección social. En particular, debe analizarse cuidadosamente si las juntas nacionales de inversión pueden invertir en el extranjero. Por ejemplo, las características geográficas y geoclimáticas de la región —integrada por pequeñas economías insulares con bases económicas poco diversificadas y muy proclives a sufrir desastres naturales- pueden ser argumentos a favor de una posición menos restrictiva ante la inversión de fondos en el exterior. Sin embargo, toda liberalización de la legislación pertinente debe ponderarse con cuidado, sopesando tanto los beneficios de aplicarla como los costos del efecto que las salidas de capital tendrían en los balances de las economías en general, y en sus regímenes cambiarios en particular. Estos son algunos de los temas que se abordarán en el resto de esta sección.

\section{a) Envejecimiento}

$\mathrm{Al}$ igual que en casi todas las regiones, el envejecimiento es un fenómeno que también afecta a las poblaciones del Caribe. La combinación de una mayor esperanza de vida al nacer y la disminución de la fecundidad está modificando la estructura demográfica. Como promedio, en la región la esperanza de vida al nacer aumentó más de 15 años en los decenios de 1980 
GRÁFICO 3

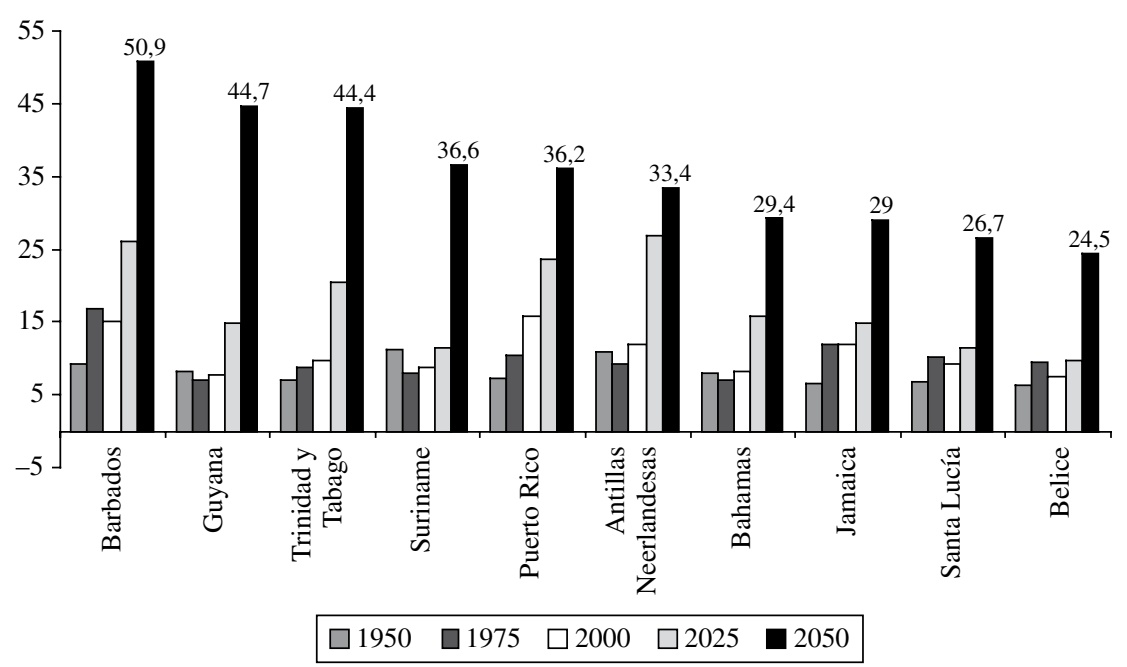

Fuente: Naciones Unidas (2002).

CUADRO 4

El Caribe: esperanza de vida al nacer

\begin{tabular}{lccc}
\hline & $2000-2005$ & $2025-2030$ & $2045-2050$ \\
\hline Bahamas & 69,4 & 75,7 & 77,3 \\
Barbados & 77,2 & 79,8 & 81,4 \\
Belice & 74,4 & 77,5 & 79,7 \\
Guyana & 62,4 & 64,1 & 71,2 \\
Jamaica & 75,7 & 79,0 & 80,8 \\
Antillas Neerlandesas & 76,3 & 79,4 & 81,0 \\
Puerto Rico & 75,6 & 78,3 & 80,3 \\
Santa Lucía & 73,8 & 77,2 & 79,5 \\
Suriname & 71,1 & 75,8 & 78,6 \\
Trinidad y Tabago & 74,8 & 78,6 & 80,5 \\
Promedio & 73,1 & 76,5 & 79,0 \\
\hline
\end{tabular}

Fuente: Naciones Unidas (2002).

y de 1990. Actualmente es de alrededor de 73,1 años, ${ }^{22}$ y se prevé que llegará aproximadamente a 79 años hacia mediados del siglo XXI (cuadro 4). Para ese entonces, la tasa de crecimiento de la población habrá disminuido al $0,1 \%$, desde el $1,8 \%$ observado a mediados del siglo XX y el $1 \%$ que se registra actualmente.

\footnotetext{
22 Estos datos corresponden a los países de habla inglesa del Caribe para los cuales se dispone de información (véase el cuadro 4).
}

Si bien las causas de dicho cambio están documentadas, ${ }^{23}$ se justifica efectuar un examen más detenido de las variaciones que se observan. La comparación intrarregional revela que la "bomba de tiempo" que pueden ser las pensiones amaga a algunos Estados miembros más que a otros. Por ejemplo, existe una diferencia significativa entre la esperanza de vida al nacer exhibida por Guyana (62,4 años) y la más alta de la región, registrada en Barbados (77,2 años), diferencia que, se prevé, habrá de reducirse. Sin embargo, a raíz de la disminución de la fecundidad, sumada a la emigración, habrá un aumento considerable de la tasa de dependencia de personas de edad avanzada (gráfico 3). ${ }^{24}$ Cuanto más alta sea esta tasa, mayor será el número de personas de edad avanzada que la población económicamente activa deberá mantener, es decir, más elevados serán los costos de la protección social. Salvo en las Antillas Neerlandesas, el aumento porcentual se acelerará en todos los países, con un incremento medio de $66 \%$ en los primeros 25 años del siglo XXI y del $118 \%$ en los 25 años siguientes.

Por lo demás, el incremento de este coeficiente de dependencia tendrá un ritmo cada vez más acelerado durante los próximos cinco decenios. Se estima que

\footnotetext{
${ }^{23}$ Véase un análisis reciente del envejecimiento de la población del Caribe, en CEPAL (2004).

${ }^{24}$ El coeficiente de dependencia de personas de edad avanzada se define como el número de personas de 65 años o más por cada 100 personas de entre 15 y 64 años.
} 
en la primera mitad del siglo XXI el aumento menor (130\%) se dará en Puerto Rico y en Guyana será de casi $500 \%$. Estos incrementos repercutirán en los planes de protección social de la región, ya que una fuerza de trabajo cada vez más pequeña deberá mantener a una proporción cada vez mayor de personas de edad avanzada.

Este último aspecto guarda relación con el estado actual de los mercados de trabajo en el Caribe, puesto que un sistema de protección social que funcione bien necesita de un mercado de trabajo que funcione bien, sobre todo en el caso de los planes de reparto, puesto que en ellos los trabajadores de hoy son responsables de los jubilados actuales.

\section{b) Mercados de trabajo}

Los mercados de trabajo de la región enfrentan varios problemas. Uno de los más importantes para la protección social es el desempleo (cuadro 5). Otro se vincula con la mayor movilidad de la mano de obra, tanto dentro de la región como fuera de ella.

El desempleo es, sin lugar a dudas, uno de los problemas económicos más graves para los Estados miembros de la región. No se trata solamente de que en muchos de ellos se esté registrando una tasa de desempleo superior al 10\%, sino de que el desempleo entre las mujeres es significativamente mayor que entre los hombres, y el desempleo juvenil en general es severo. Así, los datos disponibles sobre Barbados, Belice, Jamaica, Santa Lucía y Trinidad y Tabago revelan que las cohortes más jóvenes de la fuerza de trabajo son las más afectadas: en Santa Lucía y en Jamaica una de cada dos personas de entre 15 y 19 años de edad está desempleada (cuadro 6). Lo mismo ocurre con una de cada cada cuatro en Barbados y en Belice, y una de cada cinco en Trinidad y Tabago. Además, las cifras revelan que mientras en Barbados más del $60 \%$ de los desocupados ha estado sin trabajo durante menos de seis meses $\mathrm{y}$, de hecho, más del $80 \%$ ha estado desempleado durante menos de un año, en Santa Lucía más de las tres cuartas partes de los desocupados han estado sin trabajo durante más de un año. En Trinidad y Tabago la proporción correspondiente es cercana al $25 \%$ y en Jamaica es de alrededor de la tercera parte de la población (cuadro 7). Es más, en Jamaica aproximadamente la tercera parte de la fuerza de trabajo nunca ha estado empleada.

Las cifras indican que conseguir empleo es difícil para los que procuran incorporarse al mercado laboral y que tampoco es fácil reemplearse, lo que según indicios preliminares puede deberse en gran medida a deficiencias del sector educacional (CEPAL, 2005). Esto tiene fuertes repercusiones en la protección social. Por ejemplo, al no poder encontrar empleo, las personas no logran reunir los requisitos exigidos para acceder a las prestaciones, lo que podría afectar sus posibilidades de pensionarse en el futuro. Además, el aumento del desempleo reduce el número de trabajadores que financian las pensiones de quienes están jubilados en la actualidad.

CUADRO 5

El Caribe: tasas de desempleo

\begin{tabular}{|c|c|c|c|c|}
\hline País & Año & Hombres & Mujeres & Total \\
\hline Anguilla & 2002 & 6,3 & 9,5 & \\
\hline Antigua y Barbuda & 1991 & 6,4 & 5,6 & \\
\hline Aruba & 1997 & 6,7 & 8,4 & \\
\hline Bahamas & 2003 & 5,9 & 9,6 & \\
\hline Barbados & 2002 & 8,7 & 12,1 & 10,3 \\
\hline Belice & 2004 & 8,3 & 17,4 & 11,6 \\
\hline Islas Vírgenes Británicas & 1991 & 3,4 & 3,1 & \\
\hline Dominica & 1997 & 19,6 & 27,2 & \\
\hline Granada & 1998 & 10,5 & 21,2 & \\
\hline Guyana & 1992 & 8,4 & 18,1 & \\
\hline Jamaica $^{\mathrm{a}}$ & 2003 & 9,6 & 17,5 & 13,1 \\
\hline Antillas Neerlandesas & 2000 & 12,0 & 16,2 & \\
\hline Santa Lucía & 2003 & 17,2 & 28,1 & 22,3 \\
\hline San Vicente y las Granadinas & 1991 & 18,4 & 22,1 & \\
\hline Suriname & 1999 & 10,0 & 20,0 & \\
\hline Trinidad y Tabago ${ }^{\mathrm{a}}$ & 2004 & 8,0 & 12,1 & 10,5 \\
\hline
\end{tabular}

Fuente: OIT (2005) y datos oficiales.

a Segundo trimestre de 2003/segundo trimestre de 2004; según la definición de la OIT, la tasa total de desempleo sería del 7,5\%. 
CUADRO 6

El Caribe (cinco países): desempleo

(Porcentaje de la cohorte activa afectada)

\begin{tabular}{|c|c|c|c|c|c|c|c|c|c|c|}
\hline \multirow[b]{2}{*}{ Años de edad } & \multicolumn{2}{|c|}{ Trinidad } & \multicolumn{2}{|c|}{ Jamaica } & \multicolumn{2}{|c|}{ Barbados } & \multicolumn{2}{|c|}{ Santa Lucía } & \multicolumn{2}{|c|}{ Belice } \\
\hline & 1991 & $2004^{\mathrm{a}}$ & 1991 & $2001^{\mathrm{a}}$ & 1992 & 2000 & 1993 & 2003 & 1993 & 2004 \\
\hline $15-19$ & 43,2 & 21,2 & 39,2 & 50,1 & 60,9 & 28,0 & 41,5 & 54,3 & 24,1 & 24,0 \\
\hline $20-24$ & 29,6 & 15,7 & 25,3 & 27,7 & 33,9 & 12,8 & 21,2 & 31,9 & 11,0 & 15,0 \\
\hline $25-34$ & 18,6 & 6,6 & 14,4 & 14,0 & 23,9 & 9,9 & 13,2 & 21,5 & 9,3 & 13,4 \\
\hline $35-44$ & 12,4 & 4,2 & 8,8 & 8,3 & 15,9 & 6,1 & 11,2 & 15,7 & 4,6 & 10,1 \\
\hline $45-54$ & 9,2 & 5,0 & 6,9 & 5,8 & 14,8 & 6,3 & 6,6 & 16,7 & 2,9 & 9,1 \\
\hline $55-64$ & 8,7 & 4,8 & 4,7 & 5,2 & 10,0 & 6,5 & 16,2 & 15,1 & 5,6 & 7,6 \\
\hline Más de 65 & 2,9 & 2,5 & 2,9 & 4,1 & 4,0 & 0,0 & 11,3 & 17,6 & 7,5 & 6,7 \\
\hline
\end{tabular}

Fuente: datos oficiales.

a Segundo trimestre del 2003/segundo trimestre del 2004.

CUADRO 7

El Caribe (cinco países): duración del período de desocupación

(Porcentaje de desempleados)

\begin{tabular}{lcccccr}
\hline & Últimas observaciones & Menos de 6 meses & Entre 6 y 11 meses & 1 año y más & Nunca trabajó & Sin declarar \\
\hline Barbados & 2002 & 61,9 & 21,1 & 12,9 & 1,4 & 2,7 \\
Jamaica & 2001 & 21,8 & 15,5 & 31,7 & 30,7 & 0,3 \\
Santa Lucía & 2000 & 20,3 & & $77,9^{\mathrm{a}}$ & & 1,8 \\
Trinidad y Tabago & 2002 & 54,3 & 9,5 & 23,7 & 12,3 & 0,2 \\
Belice & 1999 & 20,9 & 23,9 & 53,8 & $\cdots$ & 1,9 \\
\hline
\end{tabular}

Fuente: datos oficiales.

a Proporción de desempleados que hayan trabajado más de seis meses.

La movilidad de la mano de obra, tanto dentro como fuera de la región, plantea otro desafío a la protección social. La emigración ha sido considerable, lo que ha dado lugar a una gran fuga de cerebros. Vemos así que Guyana, Haití, Jamaica, Trinidad y Tabago, y Suriname registran las tasas más altas de emigración del mundo, las que salvo en Trinidad y Tabago llegan a más del $80 \%$. Casi la mitad de los 30 países con las tasas de emigración más altas del mundo pertenecen a la región. La situación resulta aún más grave si se tiene en cuenta que el equivalente al 10\% de la población actual de Jamaica emigró entre 1991 y 2001 (Docquier y Marfouk, 2004). Las grandes corrientes de trabajadores que abandonan la región, sobre todo graduados con alta calificación, representan una amenaza para la protección social ya que, además de incidir en el crecimiento económico total, reducen la mano de obra disponible para financiar las pensiones de los actuales jubilados y, lo que es peor, merman el acervo de trabajadores muy calificados y de altos ingresos.

Una de las causas de las grandes corrientes emigratorias hacia otras regiones que se registran en el
Caribe tal vez sea la dificultad de migrar dentro de la región; de hecho, algunas pruebas anecdóticas indican que los trabajadores preferirían permanecer en la región si pudieran encontrar un empleo adecuado. En reconocimiento de ello, las autoridades han ajustado el marco institucional que rige la movilidad de la fuerza de trabajo. Tras acordarse que, en general, la intensificación del proceso de integración regional y, en particular, la creación de un Mercado Económico Único del Caribe contribuirían a promover el crecimiento regional, en mayo de 1998 entró en vigor provisionalmente el Protocolo II de enmienda del Tratado de Chaguaramas, que creó la Comunidad del Caribe; la enmienda se refiere al derecho de establecimiento, a los servicios y al capital. Esta última medida puede ampliar la libre circulación en el Caribe al autorizar el libre movimiento intrarregional de mano de obra calificada. ${ }^{25}$ Sin embargo, los movimientos

\footnotetext{
${ }^{25}$ Sin embargo, en el Tratado de Chaguaramas se establece una distinción entre trabajadores dependientes e independientes. Mientras que este
} 


\section{RECUADRO 1}

Acuerdo de la Comunidad del Caribe (CARICOM) sobre la protección social y Convención de la Organización de los Estados del Caribe Oriental (OECO) sobre la protección social.

En principio, en la región existen dos acuerdos principales sobre la protección social, uno es el Acuerdo sobre la protección social, de la CARICOM, y el otro la Convención sobre la protección social, de la OECO. Esta última es más amplia en líneas generales, puesto que comprende prestaciones sociales adicionales de corta duración (como prestaciones por maternidad y enfermedad, asignaciones mortuorias y otras), en tanto que el Acuerdo de la CARICOM solo incluye prestaciones de larga duración relacionadas con pensiones (por invalidez, discapacidad, sobrevivencia y jubilación). Además, las contribuciones efectuadas en cualquiera de los Estados signatarios de la Convención de la OECO se suman, de modo que el trabajador recibirá una pensión siempre que el número acumulado de contribuciones sea el exigido en el Estado en el que solicite la pensión. Esto rige incluso si no reúne el número mínimo de contribuciones en un mismo país por haberse trasladado de un Estado miembro a otro.

Según el Acuerdo de la CARICOM, el número total de contribuciones solo se suma si el trabajador no reúne los requisitos establecidos para pensionarse en ninguno de los países en los que ha trabajado. En caso de que reúna los requisitos mínimos de varios países, puede recibir una pensión en cada uno de ellos; la suma de estas diferentes pensiones puede ser mayor que la pensión en cualquiera de los Estados. Por lo demás, en el Acuerdo de la CARICOM no queda claro lo que ha de hacerse si los requisitos mínimos para acceder a una pensión se cumplen solo en un Estado, pero no en otros. Es preciso abordar esta situación.

migratorios dentro de la región siguen siendo escasos si se los compara con la inmigración desde otras regiones (CEPAL, 2005).

Con respecto a la protección social y la migración, todos los Estados que son miembros plenos del CDCC adhirieron al Acuerdo de la Comunidad del Caribe (CARICOM) sobre la protección social, que se firmó en 1993. Con anterioridad, los Estados miembros de la OECO habían suscrito la Convención de la OECO sobre la protección social. Estos dos acuerdos coexisten, al igual que otros bilaterales entre Estados miembros y

último grupo disfruta de libre circulación laboral —en el sentido de que cualquier persona (natural o jurídica) puede establecer un negocio y trabajar por cuenta propia en los Estados miembros de la CARICOM (en el Tratado esto se denomina 'derecho de establecimiento')—, tan solo algunas categorías de trabajadores dependientes disfrutarán de libre movilidad laboral. En particular, tienen actualmente esta prerrogativa los trabajadores dependientes que son graduados universitarios, empleados de medios de información, deportistas profesionales, artistas y músicos (Artículo 46 del Tratado de Chaguaramas). Por otra parte, en el Tratado no se abordan concretamente las modalidades exigidas por los países para lograr plena movilidad intrarregional de la mano de obra, así como tampoco se fija un cronograma bien definido para la puesta en práctica. El Mercado Económico Único del Caribe no se puso en marcha en el 2000, como estaba programado, y se ha instrumentado solo entre Jamaica, Barbados y Trinidad y Tabago a partir del $1^{\circ}$ de enero de 2005 .
Estados extrarregionales. ${ }^{26} \mathrm{Si}$ bien deben corregirse algunas deficiencias del Acuerdo de la CARICOM (recuadro 1), la región en su conjunto merece elogios por estas iniciativas.

\section{c) Inversiones}

Como ya se mencionó, en el último decenio la inversión de las reservas de la protección social en el Caribe ha tenido resultados deficientes. Es más, en muchos países tales inversiones son insostenibles. Los gobiernos tienen el dominio de dichas reservas, y los títulos públicos suelen representar una porción significativa de las inversiones. Si bien los préstamos que toma el gobierno de los fondos de la protección social se utilizan a veces para el desarrollo de infraestructura en países como los de la OECO, la mayor parte de los recursos se destina a gastos corrientes y no de capital, de modo que no influyen en el crecimiento de largo plazo. Además, la captación de estos fondos por el gobierno reduce el saldo disponible para financiar actividades privadas en los sectores de turismo, agricultura, manufacturas destinadas a nichos de mercado y otras actividades en las que la región pueda

\footnotetext{
${ }^{26}$ Aunque existen acuerdos bilaterales entre Estados miembros y otros Estados, se limitan principalmente a los celebrados por algunos de los Estados miembros con Canadá y el Reino Unido.
} 
competir. Si bien los fondos de los planes de protección social se invierten en hipotecas, vivienda, educación y otras actividades sociales, al parecer no existe una estrategia concertada para facilitar la reestructuración de sectores estancados e invertir en nuevas actividades productivas con perspectivas de rentabilidad. Habida cuenta del vencimiento a largo plazo de la mayor parte de sus obligaciones, los planes de protección social podrían financiar parte del capital social de empresas pujantes de producción y servicios.

En los primeros años de operación, la mayoría de los planes regionales enfrentaba limitaciones en cuanto al grado de diversificación de sus carteras. En particular, la mayor parte de ellos tenía prohibido invertir en activos extranjeros. Esa restricción se fundó tal vez en el principio de que los países de la región con déficit de capital no deberían exportar capital a mercados desarrollados superavitarios de Estados Unidos, las naciones europeas y otros países. Sin embargo, más importante es el temor que despiertan los riesgos cambiarios, la volatilidad de los mercados y otros riesgos vinculados con los mercados extranjeros, ya que no se los conoce bien y se considera que los países no tienen control alguno sobre ellos.

Sin embargo, el excedente de liquidez del sector bancario regional ha hecho bajar la rentabilidad de los depósitos a plazo fijo y otros depósitos de los bancos comerciales. Por esto y porque los mercados regionales de valores son incipientes, la inversión extranjera debería estudiarse seriamente como otra fuente de inversión a fin de que los planes de protección social puedan obtener los mejores rendimientos. Dado el creciente ritmo de aumento de las transacciones financieras regionales transfronterizas, especialmente con origen en Trinidad y Tabago, se podría considerar a los mercados regionales monetarios y de capital como opciones para diversificar los riesgos y acrecentar la rentabilidad de los planes de protección social. Al mismo tiempo, debería permitirse la inversión de las reservas de la protección social en los mercados de capital extrarregionales. ${ }^{27}$ Por ejemplo, como se señaló antes, solo hay un limitado número de mercados de valores en la región, en cada uno de los cuales solo cotiza un reducido número de títulos. Además, el

\footnotetext{
27 Esta era en realidad la opinión de la mayoría de los especialistas entrevistados en la OECO, representativa de más de las tres cuartas partes del total de miembros del directorio y del $72 \%$ del total de entrevistados (Henry, 2004, p. 194).
}

riesgo que significa la gran vulnerabilidad del Caribe a los desastres naturales tiene fuertes repercusiones en cualquier cartera de valores que se concentre exclusivamente en la región.

Además de lo dicho, persiste el problema de las fluctuaciones cambiarias. Mientras que la volatilidad de los tipos de cambio puede en cierta medida ser objeto de cobertura financiera, las salidas de recursos financieros ejercerían presión en el sistema financiero, puesto que la mayoría de los países de la región tiene tipos de cambio fijos o bien fluctuantes dentro de una banda estrecha (fijados de jure y de facto). Sobre todo, dada la cuantía de los fondos de protección social de la región esto bien puede convertirse a corto plazo en un problema si los recursos se invierten en el extranjero, creando grandes dificultades en materia de reservas a los bancos centrales.

Respecto de la gestión de los fondos de protección social, también es necesario analizar si deberían ser manejados en forma competitiva por varios administradores privados de fondos o en forma centralizada por un organismo público. Los gobiernos optaron por crear juntas nacionales de inversión que tienden a aprovechar las economías de escala derivadas de la mancomunación de fondos de inversión. Sin embargo, se ha aducido que estas juntas no son del todo independientes (Osborne, 2004; Henry, 2004), puesto que muchos de sus integrantes, provenientes de los distintos países, son designados por los gobiernos respectivos. Además, varios se desempeñan a la vez en cargos políticos. Esto evidentemente afecta la imparcialidad de las decisiones de inversión que se toman. Por lo tanto, puede sostenerse que varios administradores privados de fondos de inversión que actúen competitivamente lograrían una mejor rentabilidad para los beneficiarios y también encauzarían los fondos hacia actividades que promovieran el crecimiento. Sin embargo, es importante sopesar si el tamaño de los distintos países hace recomendable tener en ellos varios administradores privados de fondos de protección social, teniendo en cuenta que la dimensión es un aspecto que pesa mucho, sobre todo en la administración de fondos de esta índole, que necesitan aprovechar las economías de escala. ${ }^{28}$

\footnotetext{
${ }^{28}$ Por ejemplo, en Bolivia, cuya población supera los 8 millones de personas, inicialmente solo se permitieron dos fondos de pensiones en el mercado.
} 


\section{IV}

\section{Reformas de la protección social}

En esencia, las reformas de esta índole pueden encuadrarse en dos categorías: reformas paramétricas y reformas estructurales. Mientras que las primeras entrañan cambios de parámetros en los planes existentes - como aumentar las tasas de contribución, los topes salariales y las edades de jubilación, así como reducir las pensiones-, la reforma estructural implica una revisión general del sistema de protección social. Si bien las reformas paramétricas quizás sean más fáciles de introducir, en muchos casos el cambio estructural del sistema se ha considerado más importante para la viabilidad a largo plazo de los planes. En esta sección se analizarán las diferentes opciones disponibles y cuán útiles pueden ser para la región, teniendo en cuenta los desafíos reseñados en la sección anterior.

En la práctica, la reforma estructural ha consistido en abandonar el sistema tradicional de un pilar (es decir, el plan de reparto) por uno más amplio, con múltiples pilares, como propugna el informe del Banco Mundial ya mencionado (Banco Mundial, 1994). En consecuencia, la mayoría de los países de América Latina ha implantado reformas de ese tipo o planea hacerlo. Varios países de Europa y Asia central también han instituido sistemas de múltiples pilares. Sin embargo, por lo general la reforma de las pensiones se vincula con la adopción de un plan de capitalización con contribuciones definidas, en el que los trabajadores deben ahorrar una parte de sus ingresos en cuentas individuales, a las cuales solo tienen acceso una vez jubilados (este cambio suele denominarse 'privatización' de la protección social). Por lo tanto, la característica esencial del sistema de múltiples pilares ha sido la introducción en el nuevo sistema de un elemento de capitalización, ya sea obligatorio o voluntario.

Uno de los principales argumentos esgrimidos por los partidarios de la reforma es la posibilidad de lograr tasas de ahorro más altas, lo que puede ser positivo para la inversión. Sin embargo, en teoría, el efecto de la protección social en el ahorro no es decisivo. Esto no significa necesariamente que en el Caribe dicho cambio no vaya a resultar beneficioso para el ahorro. ${ }^{29}$ De hecho,

\footnotetext{
${ }^{29}$ No hay una relación simple entre la reforma de las pensiones y el ahorro, ya que depende de la solidez de los efectos ingreso y sustitución, de la propensión al ahorro de los beneficiarios, y del desempeño macroeconómico. El efecto ingreso (efecto riqueza) de las tasas más
}

el incremento de las tasas de contribución hará aumentar el ahorro obligatorio de personas poco previsoras que no acumulan el ahorro necesario para financiar su consumo en la vejez. ${ }^{30}$ Además, se ha aducido que la movilización del ahorro y la inversión se ve afectada por la estructura misma de los planes de protección social; así, los planes privados de capitalización con cuentas individuales de ahorro para la jubilación permiten que las personas coloquen sus fondos allí donde la rentabilidad sea mayor, lo que alienta la competencia y la asignación de fondos a actividades productivas de elevada rentabilidad, capaces de promover el crecimiento. ${ }^{31}$ Con todo, lo que ha ocurrido en América Latina indica que las personas no tienen conocimientos financieros suficientes como para sacar partido de la situación. Además, a pesar de la importancia de la rentabilidad y el costo, la naturaleza de largo plazo de los planes de pensiones con capitalización se ha traducido en una escasa elasticidad de la demanda respecto del desempeño de los fondos de pensiones. En ese sentido, una idea viable para el Caribe puede ser la creación de un fondo administrado en forma centralizada (ya sea a nivel nacional o regional) que se encargue de invertir en nombre de todos los participantes.

Pese a los argumentos esgrimidos acerca de posibles efectos favorables en la inversión, no cabe duda de que el verdadero motivo para abandonar los planes de reparto son los problemas de financiamiento que estos afrontan, habida cuenta de los cambios de la estructura demográfica y el envejecimiento de la población. No obstante, los planes de capitalización con contribuciones definidas no están exentos de críticas. Por ejemplo, pueden dar origen a una considerable inequidad de los

\footnotetext{
altas de contribución y el aumento de la edad de jubilación podrían llevar a una merma del ahorro de largo plazo, puesto que las unidades familiares consumen más en los primeros años al prever un aumento de sus ingresos en el futuro; sin embargo, el efecto sustitución puede ser positivo o negativo, dependiendo de que la rentabilidad de los fondos de protección social invertidos sea superior o inferior a la de otros activos.

${ }^{30}$ En el supuesto de que no tendrán que compensar el ingreso más bajo mediante la toma de préstamos a cuenta de ingresos futuros.

${ }^{31} \mathrm{Sin}$ embargo, un plan de esa naturaleza todavía requiere la intervención pública para que haya una supervisión y una reglamentación eficaces encaminadas a asegurar que los fondos no se coloquen en inversiones especulativas indebidamente riesgosas ni sean objeto de fraude societario.
} 
ingresos jubilatorios: el componente redistributivo de dichos planes normalmente es mínimo debido a que las cuentas de los contribuyentes están 'privatizadas'. Lo anterior es aún más cierto si se tiene en cuenta la tasa de desempleo en general - y particularmente la elevada tasa de desempleo juvenil- en la región caribeña, porque los planes de capitalización necesitan contribuciones constantes para constituir un fondo significativo, al igual que contribuciones tempranas en la vida activa de las personas para poder beneficiarse del efecto de interés compuesto. Los planes de capitalización con contribuciones definidas también limitan el margen de distribución de los riesgos, ya que asignan a las personas una gran proporción de los riesgos relacionados con la rentabilidad de la inversión. En este sentido, las personas pueden protegerse del agotamiento de recursos en caso de longevidad mediante la compra de una pensión vitalicia basada en la cartera acumulada en el fondo de pensiones al momento de jubilarse, pero la volatilidad del mercado de valores, sobre todo hacia el final de la vida activa de los trabajadores, puede ocasionar grandes pérdidas si las carteras no están lo suficientemente diversificadas, y así dar lugar a pagos mensuales más bajos por concepto de pensiones vitalicias, dejando a las personas en peor situación. ${ }^{32}$

Si bien la introducción de planes de capitalización ha significado avances en muchos países, los planes de capitalización con contribuciones definidas deberían, en el mejor de los casos, ser parte de un conjunto integral de medidas y no ser considerados el principal pilar para la provisión propia de ingresos jubilatorios propios (Gill, Packard y Yermo, 2005). De hecho, las investigaciones realizadas en América Latina han revelado que, a pesar de la adopción de dichos planes, los datos sobre la cobertura indican que los sistemas de protección social de la región no siempre están cumpliendo con su función de brindar protección eficaz a los ancianos. Según Rofman (2005), tan solo en tres de 17 países estudiados más de las dos terceras partes de la población anciana está amparada por la protección social, y en 10 países esta protección cubre a menos de la cuarta parte de las personas de edad avanzada. En el Caribe, los planes de capitalización encaran además otros desafíos, como la falta de profundidad de los mercados financieros, que refleja lo incipiente de los mercados de capital regionales, y el hecho de que las grandes salidas de dinero pueden estrujar las reservas internacionales, y así dar lugar a presiones cambiarias.

Una alternativa a la reforma estructural de los planes de protección social son las denominadas "cuentas nocionales de contribuciones definidas", introducidas hasta ahora en países como Suecia, Letonia, Italia y Polonia. Con ellas se pretende esencialmente imitar la estructura de los planes de capitalización con cuentas individuales sin establecer realmente un fondo, pero compartiendo los riesgos con el fin de aminorarlos. La idea básica es que las contribuciones financian las pensiones de los jubilados actuales — plan de reparto-, pero las contribuciones de cada persona se registran en cuentas individuales 'nocionales'. La rentabilidad de estas cuentas estará ligada a su vez a cambios en la productividad, a cambios demográficos actuales y futuros, o a ambas cosas; este 'valor nocional' se acredita en cuentas individuales nocionales. ${ }^{33}$ En tal sentido, se ha sostenido que el sistema debe superar problemas de viabilidad política y de incongruencia normativa de los ajustes paramétricos, al tiempo que debe mantener el componente de protección social mediante la vinculación de las prestaciones a las contribuciones. Como beneficio adicional, las personas dejan de asumir el riesgo asociado a la rentabilidad de los mercados de capital, pues se mantiene el mecanismo de financiamiento intergeneracional, como en un plan de reparto (Palmer, 1999).

Mientras que la introducción de las cuentas nocionales de contribuciones definidas tal vez sea demasiado reciente como para evaluar a cabalidad sus resultados, un análisis teórico más minucioso de dichas cuentas muestra que en esencia solo son 'planes de reparto con prestaciones definidas miniciosamente reformados' (Scherman, 1999). Esto se expone con especial claridad en la obra de Disney (1999), donde se examinan exhaustivamente las cuentas nocionales de contribuciones definidas.

\footnotetext{
32 Así sucedió en el caso de los trabajadores que jubilaron a principios del decenio de 1990 en Chile: muchos experimentaron una gran disminución de sus jubilaciones, provenientes de los planes de capitalización.
}

\footnotetext{
${ }^{33}$ En Letonia, el aumento de la base salarial para la contribución al seguro social se utiliza como tasa 'nocional' de interés; en Suecia se utiliza la tasa de aumento de los salarios nominales y en Italia la tasa de crecimiento del PIB nominal. En Polonia se utiliza la tasa de inflación más las tres cuartas partes del aumento de la base salarial para la contribución al seguro social.
} 


\section{V}

\section{Conclusiones}

Si bien la reforma de la protección social ha ocupado un lugar prominente en los programas económicos y políticos de todo el mundo - tanto en los países desarrollados como en desarrollo-, la región del Caribe al parecer se ha mantenido en gran medida al margen de estas tendencias. La actividad reformista es escasa, salvo por la introducción de ajustes relativamente pequeños en los planes existentes. Sin lugar a dudas, esto se debe en parte a la situación relativamente sólida de la mayoría de los planes nacionales: la existencia de superávit anuales ha permitido que la protección social acumule reservas que pueden ser muy significativas en relación con el PIB.

Dicho lo anterior, queda claro que los planes de pensiones de la región están encarando diversos desafíos. Aunque las poblaciones del Caribe no están, en general, envejeciendo con tanta rapidez como las de otras partes del mundo, el envejecimiento es un fenómeno al que deberá hacerse frente en el futuro. Otro problema, de más amplitud, tiene que ver con los mercados de trabajo en general: el desempleo en la región está extendido, es persistente y afecta en especial a los jóvenes y las mujeres; además, el tamaño del sector informal ha aumentado en los últimos años. Esos fenómenos afectan los planes de protección social, puesto que ni los desocupados ni los trabajadores del sector informal efectúan contribuciones, pero en el futuro pueden representar una carga para los planes. Por lo tanto, las autoridades harían bien en abordar sin demora estos problemas.

Las autoridades de la región disponen de varias opciones. Por ejemplo, pueden seguir efectuando reformas paramétricas, o pasar a una reforma más bien estructural o bien combinar ambas soluciones. Según se desprende de experiencias en todo el mundo, solo la cuarta parte de los países que reformaron sus sistemas de pensiones recurrió a grandes reformas estructurales; los demás aplicaron soluciones paramétricas. ${ }^{34}$ En lugar de abogar por una reforma estructural en la región —-por ejemplo, reemplazar planes de reparto con prestaciones definidas por planes de capitalización con contribuciones definidas,

\footnotetext{
${ }^{34}$ Según Schwarz y Demirguc-Kunt (1999), sólo en 21 de los 82 países donde se aprobaron reformas del sistema de protección social, estas fueron 'fundamentales' y entrañaron un cambio sustancial del sistema.
}

como parece estarse promoviendo en otras partes del mundo- quizás sea más adecuado aplicar una reforma que se adapte más a las necesidades específicas de la región, habida cuenta de sus características.

La realidad es que los planes de protección social de la región ya disponen de fondos considerables. Sin embargo, hay un desajuste de cartera que se manifiesta en una tenencia excesiva de instrumentos de corto plazo (activos) para hacer frente a pasivos de largo plazo. Por otra parte, los fondos en gran medida no están invertidos en actividades productivas que generen crecimiento, sino que han sido captados por los gobiernos, como lo demuestran las significativas tenencias de bonos de tesorería de baja rentabilidad en la mayoría de los países. Si bien se reconoce que en la región hace falta profundizar los mercados de capital para crear los instrumentos de inversión necesarios, la situación actual ha conducido a un bajo rendimiento de esas inversiones. Con esto se socavan los beneficios potenciales para las economías que derivarían de la inversión de las reservas de la protección social. Además, habrá que revisar muchos de los parámetros de los planes regionales de protección social y tal vez sea necesario modificar la legislación vigente.

El primer paso, por lo tanto, sería eliminar algunas de las restricciones legales a la inversión que efectúan los fondos de pensiones, teniendo en cuenta los posibles efectos en las balanzas de pagos de las economías; esto podría traducirse en una mejora significativa del desempeño de tales fondos. El segundo paso, también vinculado al volumen actual de reservas, sería revisar la administración de los fondos: como se indica en Banco Mundial (1994), lo mejor para evitar que la inflación erosione el valor de las reservas es la diversificación internacional de las inversiones de los fondos de pensiones; es más probable que esto se logre si la administración de las inversiones está a cargo del sector privado. Sin embargo, en el Caribe la escasez de analistas de inversiones y administradores de fondos con la experiencia y la preparación requeridas afecta a la eficiencia de las decisiones de inversión y limita la diversificación de la cartera. Una posible solución sería mancomunar las inversiones de cartera de todos los países del Caribe para colocarlas fuera de la región. Aprovechar las economías de escala, de esa manera 
podría redundar en una reducción general del gasto de los distintos países por concepto de remuneración de los administradores de fondos y los analistas de inversiones. Pero sería preciso analizar con minuciosidad cómo se puede llevar esta opción a la práctica.

Como se mencionó antes, habrá que revisar diversos parámetros y características de diseño de los planes de protección social de la región. Si bien el aumento no lineal de la tasa de sustitución de ingresos al jubilar puede contribuir a que las personas se jubilen anticipadamente, la decisión de basar los ingresos medios imponibles en, por ejemplo, los mejores tres a cinco años de los últimos 10 a 15 años de trabajo de cada persona crea un entorno en el cual el vínculo entre las contribuciones y las prestaciones puede considerarse débil.

En términos más generales, debería reconsiderarse la lógica actual de los planes contributivos, es decir, la exigencia de contribuir a un plan de protección social para poder acceder a una pensión. Como las economías regionales se caracterizan por tener amplios sectores informales y tasas persistentes de desempleo, sobre todo de jóvenes y mujeres, los planes contributivos por fuerza excluyen a gran parte de la población del acceso a una pensión significativa en su vejez. Esto afecta grandemente el bienestar de los habitantes, en una región con importantes focos de pobreza. Por lo tanto, debería estudiarse la posibilidad de aplicar un sistema de protección social de base más amplia: por ejemplo, un sistema no contributivo con requisitos de admisión ligados a la residencia, la nacionalidad, o ambas cosas, y cuyas prestaciones se financien con la tributación general. ${ }^{35}$ La introducción de un esquema de esta índole - posiblemente en paralelo con los planes actuales - sería un pilar importante para abordar el problema de la pobreza en la región.

Asimismo, habida cuenta del gran número de países que alberga la región y por consiguiente del gran número de planes de protección social, un objetivo de largo plazo podría ser crear un esquema general de protección social en el Caribe. Si bien la diversidad de los países caribeños plantea un gran desafío, el Acuerdo de la CARICOM sobre la protección social puede considerarse un primer paso hacia la creación de un esquema común; asimismo, dentro del Mercado Económico Único del Caribe se podría lograr una interacción más estrecha de los diversos planes nacionales de protección social. Sin embargo, mientras no aumente la movilidad intrarregional de la mano de obra, seguirán siendo limitados los beneficios que podrían derivar de dicho esquema común y de la mayor portabilidad actual de las contribuciones y pensiones en virtud del Acuerdo de la CARICOM mencionado.
Banco Mundial (1994): Averting the Old Age Crisis: Policies to Protect the Old and Promote Growth, Washington, D.C.

CEPAL (Comisión Económica para América Latina y el Caribe) (2005): Labour Market Trends, LC/CAR/L.51, Puerto España, sede subregional de la CEPAL para el Caribe.

(2004): Population Ageing in the Caribbean: Longevity and Quality of life, LC/CAR/L.26, Puerto España, sede subregional de la CEPAL para el Caribe.

Disney, R. (1999): Notional Accounts as a Pension Reform Strategy: An Evaluation, Social Protection Discussion Paper Series, $\mathrm{N}^{\circ}$ 9928, Washington, D.C., Banco Mundial.

Docquier, F. y A. Marfouk (2004): Measuring the International Mobility of Skilled Workers (1990-2000), Policy Working Research Paper Series, $\mathrm{N}^{\mathrm{o}}$ 3381, Washington, D.C., Banco Mundial.

Gill, I., T. Packard y J. Yermo (2005): Keeping the Promise of Social Security in Latin America, Washington, D.C., Banco Mundial/ Stanford University Press.

Gruber, J. y D. Wise (comps.) (1999): Social Security and Retirement around the World, Chicago, University of Chicago Press.

Henry, V.F. (2004): An Investigation into the Structure, Governance and Performance of the Social Security Organizations in the Caribbean, inédito.

Montas, H.P. (2003): Belize: Sixth Actuarial Review of the Social Security Scheme. Disponible en http://www.socialsecurity.org.bz/.

Naciones Unidas (2002): World Population Ageing: 1950-2050, ST/ESA/SER.A/207, Nueva York. Publicación de las Naciones Unidas, $\mathrm{N}^{\circ}$ de venta: E.02.XIII.3.
National Insurance Board of the Bahamas (2001): Seventh Actuarial Review of the National Insurance Fund as of 31 December 2001. Disponible en http://www.nib-bahamas.com/

OIT (Organización Internacional del Trabajo) (2005): Saint-Lucia: Report to the Government. Eighth Actuarial Review of the National Insurance Fund as of 30 June 2003, Ginebra.

Orszag, P. y Stiglitz (2001): Rethinking pension reform: ten myths about social security systems, en R. Holzmann y J. Stiglitz (comps.), New Ideas About Old Age Security: Toward Sustainable Pension Systems in the 21 st Century, Washington, D.C., Banco Mundial.

Osborne, D. (2004): A current assessment and road map for achieving future financial sustainability and income security, inédito.

\footnotetext{
35 Dichos planes al parecer han tenido éxito en Argentina, Bolivia, Brasil y Chile, donde las tasas de cobertura son relativamente altas. La introducción de este pilar no contributivo ahora es parte del nuevo enfoque del Banco Mundial relativo a los pilares de los planes de pensiones (Gill, Packard y Yermo, 2005). El sistema inicial de tres pilares (véase más atrás la sección III) ahora tiene dos pilares más: el pilar universal no contributivo y un pilar no financiero que es el de la política social, expresada por ejemplo en la disponibilidad de vivienda, atención de salud y otros factores sociales.
} 
Palmer, E. (1999): The Swedish Pension Reform: Framework and Issues, Estocolmo, National Social Insurance Board.

Rofman, R. (2005): Social Security Coverage in Latin America, Social Protection Discussion Paper Series, N ${ }^{\circ}$ 0523, Washington, D.C., Banco Mundial.

Schwarz, A. y A. Demirguc-Kunt (1999): Taking Stock of Pension Reforms Around the World, Social Protection Discussion Paper Series, N ${ }^{\circ}$ 9917, Washington, D.C., Banco Mundial.

Scherman, K. (1999): The Swedish Pension Reform, Issues in Social Protection, Discussion Paper, $N^{\circ} 7$, Ginebra, Organización Internacional del Trabajo (OIT).
Thompson, L.H. (2001): Operation of pension systems: public or private?, en I. Ortiz (comp.), Social Protection in Asia and the Pacific, Manila, Banco Asiático de Desarrollo.

Unión Europea (2002): Mutual Information System on Social Protection in the Central and Eastern European Countries Bulgaria, Czech Republic, Estonia, Hungary, Latvia, Lithuania, Poland, Romania, Slovak Republic and Slovenia: Situation at 1 January 2002. Disponible en http://ec.europa.eu/employment_social/ social protection $/$ missceec en.htm

(2006): Adequate and Sustainable Pensions: Synthesis Report 2006, Luxemburgo, Oficina de Publicaciones Oficiales de las Comunidades Europeas. 